\title{
Concepções de Dualidade Onda-Partícula: Uma proposta didática construída a partir de trechos de fontes primárias da Teoria Quântica
}

Different Conceptions of Wave-Particle Duality: A didactic proposal built from excerpts from primary sources of Quantum Theory

 \\ ${ }^{1}$ Universidade Federal do Rio Grande do Sul Instituto de Física, 91501-970, Porto Alegre, RS, Brasil.
}

\begin{abstract}
Recebido em 01 de julho de 2020. Revisado em 30 de outubro de 2020. Aceito em 31 de outubro de 2020.
Muitos pesquisadores defendem que não é possível ensinar física quântica sem ensinar pelo menos um pouco de história da física quântica. A literatura, entretanto, aponta que as narrativas dos livros didáticos destoam em diferentes sentidos das fontes primárias, reduzindo a complexidade da natureza da ciência a uma visão mitológica da prática científica. Por outro lado, a leitura dos textos originais sem nenhum direcionamento, ou mesmo a leitura dos livros historiográficos, pode ser muito arenosa. Defendemos que uma possibilidade para enriquecer o ensino de física quântica é proporcionar ao aluno contato com os trabalhos originais, desde que não se perca de vista a finalidade didática de tal encontro. Buscando contribuir para essa proposta, apresentamos um texto didático, direcionado a alunos de graduação, sobre a dualidade onda-partícula, composto por uma seleção de trechos de fontes primárias de física quântica e por um conjunto de perguntas para guiar a leitura. Ao longo do artigo, apresentamos os marcos teóricos que guiaram a construção do material didático e, no corpo do texto, comentamos as perguntas propostas.

Palavras-chave: Ensino de Física Quântica, Mecânica Quântica, História e Epistemologia, Física Moderna e Contemporânea, Fontes Primárias.
\end{abstract}

\begin{abstract}
Many researchers argue that it is not possible to teach Quantum Physics without teaching at least a little of history of Quantum Physics. The literature, however, points out that the textbook narratives differ in different directions from the primary sources, and they reduce the complexity of the nature of science to a mythological view of scientific practice. On the other hand, reading the original texts without any direction, or even reading the historiographical books, can be very difficult. We argue that a possibility to enrich the teaching of Quantum Physics is to provide the student with contact with the original works, as long as we do not lose sight of the didactic purpose of such a meeting. Seeking to contribute to this proposal, we present a didactic text, aimed to be presented to undergraduate students, on the wave-particle duality, composed of a selection of excerpts from primary sources of Quantum Physics and a set of questions to guide the reading. Throughout the article, we present the theoretical frameworks that guided the construction of the didactic material and, in the body of the text, we comment on the proposed questions.
\end{abstract}

Keywords: Quantum Physics Teaching, Quantum Mechanics, History and Epistemology, Modern and Contemporary Physics, Primary Sources.

\section{Introdução}

De uma forma geral, pode-se encontrar, na área de ensino de física, a classificação das diferentes abordagens para o ensino da teoria quântica em três grandes grupos: histórica, postulacional e fenomenológica 11. As três diferentes abordagens, e todas as possíveis combinações e variações delas, têm aspectos positivos e desafios a serem superados. A abordagem fenomenológica, por exemplo, pode levar os estudantes rapidamente àquilo que Feynman denominou o "único mistério da física quântica", isto é, a dualidade onda-partícula. Tal abordagem, entretanto, pode parecer assistemática e fragmentada,

\footnotetext{
*Endereço de correspondência: lima.nathan@gmail.com.
}

não permitindo que os alunos ganhem, em um primeiro momento, a visão do arcabouço teórico completo da teoria. A abordagem postulacional, por outro lado, imediatamente, fornece aos estudantes o aparato matemático necessário para resolver os diferentes problemas exemplares da mecânica quântica e apresenta "um quadro completo" do formalismo da teoria. Tal abordagem, entretanto, pode ser demasiado abstrata, muito próxima ao famoso "shut up and calculate" [2] que por muito tempo dominou o mainstream da física teórica, criando nos estudantes uma sensação de "falta de sentido", ou de falta de justificação "do porquê a Teoria é do jeito que é".

A abordagem histórica, por sua vez, permite justamente oferecer esse "sentido" ao desenvolvimento da teoria, mostrando quais problemas motivaram as 
proposições de novos conceitos e evidenciando a necessidade de construir uma teoria quântica. Há pesquisadores, inclusive, que defendem que não há como ensinar física quântica sem ensinar, pelo menos um pouco, de história da física quântica [3].

A abordagem histórica, entretanto, apresenta desafios importantes e difíceis de serem superados [4, 5]. No caso da física quântica, especificamente, o significado de muitos conceitos mudou muito rapidamente. O quantum proposto por Einstein em 1905, por exemplo, não tem as mesmas propriedades que o fóton adquiriu nos anos subsequentes. Simplesmente dizer que Einstein "descobriu" o quantum, sem fazer um apontamento claro das limitações que tal conceito tem, pode se tornar uma possível fonte de confusão e de obstáculo pedagógico. Um segundo desafio em uma abordagem histórica é a adoção de uma visão historiográfica e epistemológica consistente. Quando não há uma preocupação com tais elementos, a história apresentada assemelha-se muito mais a uma narrativa mitológica do que a uma discussão histórica 6.

Uma possível alternativa a tais problemas seria recorrer ao uso de livros e artigos historiográficos em sala de aula. Certamente, essa é uma opção válida e que pode enriquecer muito a atividade pedagógica. Entendemos, entretanto, que, muitas vezes, o objetivo de um livro de história da ciência não é o mesmo objetivo de um curso de física quântica, e tais trabalhos podem ser demasiado técnicos ou percorrerem uma vasta literatura que, talvez, em um primeiro momento, pode ser muito complexa para quem está começando o estudo de uma nova área da física (ou até mesmo para quem já possui grande experiência). Assim, o terceiro desafio refere-se não à qualidade da historiografia a ser utilizada, mas à quantidade, a fim de atingir os objetivos didáticos almejados.

No presente trabalho, buscamos apresentar uma proposta didática construída a partir de trechos dos artigos seminais de física quântica que se referem explicitamente à questão da dualidade onda-partícula, elaborada para ser utilizada com alunos de graduação de licenciatura e bacharelado em física - ou em cursos de formação de professores. O propósito da unidade didática é justamente apresentar uma "midterm solution". Isto é, apresentamos um material historicamente consistente, lastreado em marcos teóricos, epistemológicos e pedagógicos claros (que são discutidos na seção 2), apresentado de forma a levar os alunos a refletir sobre a evolução conceitual da dualidade onda-partícula, buscando não se exceder em uma discussão técnica e muito robusta. Com certeza, toda narrativa histórica reduzida é, em certo sentido, falha e incompleta. Conforme discutiremos na seção 2, entretanto, a unidade didática foi construída buscando um compromisso entre rigor historiográfico e aplicabilidade no contexto pedagógico.

Ao longo da unidade, apresentamos trechos de artigos seminais da física quântica em que a concepção de dualidade onda-partícula é apresentada de forma substancial. Depois de cada trecho, apresentamos perguntas com o intuito de fomentar a reflexão sobre o conceito apresentado, ressaltando aspectos fundamentais. Ao longo do corpo do artigo, fazemos, também, comentários, respondendo às perguntas do material didático.

O tema escolhido para ser abordado é o da dualidade onda-partícula tanto pelo fato de ele ainda possuir relevância do ponto de vista conceitual, tendo um papel central no entendimento da teoria contemporânea; mas, sobretudo, pela sua centralidade no debate histórico do início do século XX como apontam diversos historiadores. Em especial, o que diferencia o presente texto das narrativas históricas dos livros didáticos é que ele foi construído com a preocupação explícita de superar os três desafios da abordagem histórica. Dessa forma, na seção 2, fazemos uma discussão sobre quais são as premissas historiográficas, teórico-epistemológicas e didáticas adotadas, ressaltando como que essa visão moldou a construção do material didático. Na seção 3, apresentamos o material didático. Na seção 4, apresentamos nossas conclusões.

\section{Referencial Historiográfico e pedagógico para a construção do material didático}

O presente material didático foi concebido para ser utilizado em disciplinas introdutórias de física quântica, oferecida para alunos de bacharelado e licenciatura em física, ou em cursos de formação continuada de professores de física. O objetivo dessas disciplinas é, usualmente, formar cientistas e professores de ciências com um conhecimento técnico sólido. É desejável, entretanto, que os alunos também desenvolvam uma visão elaborada e consistente sobre o desenvolvimento da ciência em detrimento das visões míticas dos livros didáticos "blockbusters". Por esse motivo, optamos por uma apresentação internalista, isto é, que enfatiza os aspectos epistêmicos e internos da prática científica em detrimento da descrição do contexto social. Com isso, não queremos dizer que a ciência está apartada da sociedade, ou que uma narrativa puramente epistêmica dê conta de toda complexidade da ciência. Novamente, o que buscamos é uma "midterm solution", em que decidimos até onde conseguimos nos comprometer com uma apresentação da complexidade da ciência sem perder de vista as necessidades didáticas que o contexto pedagógico concreto nos exige. Assim, nossa abordagem é uma proposta sintética entre uma apresentação histórica e uma narrativa didática, conforme propusemos ao discutir as proposições teóricas de Louis de Broglie [7].

O foco desse trabalho se volta sobre questões conceituais relacionadas sobre a dualidade onda-partícula. Entretanto, como é impossível dissociar a estrutura matemática do argumento físico, em alguns momentos, apresentamos os argumentos matemáticos envolvidos no 
problema. Ademais, a escolha dos artigos originais a serem utilizados não se deu por motivos puramente historiográficos; mas, sobretudo, tendo em vista o contexto pedagógico. Os artigos escolhidos permitem um diálogo com os conceitos abordados em livros introdutórios de física quântica (ou até mesmo livros de física quântica) popularmente utilizados nos cursos de graduação. Sabemos que, ao fazer tal escolha, deixamos de fora muitos trabalhos que, também, foram relevantes para o desenvolvimento de tal concepção dual, como os trabalhos experimentais que foram cruciais para o desenvolvimento da concepção da dualidade ondapartícula [8]. Pelo mesmo motivo, o trabalho restringese ao contexto do desenvolvimento da teoria quântica não relativística, não tangenciando as discussões provenientes da teoria quântica de campos (TQC), a qual, apesar de poder ser considerada aquela que estabelece a versão atual da concepção sobre a natureza da radiação, não faz parte, usualmente, do currículo obrigatório de cursos de bacharelado e, principalmente, licenciatura. Poderia se pensar em uma outra proposta dedicada unicamente a fazer tal conexão com a TQC. Com isso, o que apresentamos não é um estudo historiográfico, mas uma construção de uma narrativa histórica com finalidade didática. É no encontro dessas duas esferas do conhecimento, a historiografia da ciência e a didática das ciências, que o presente material foi construído. Assim, o nosso trabalho se alinha com um conjunto de pesquisas que defendem o uso de fontes primárias no ensino de física [9 14. Um fator que é comum nessas defesas é a concepção de que ensinar física não é somente ensinar os alunos sobre os conceitos em sua versão contemporânea de forma instrumental, mas motivar uma concepção mais profunda sobre a natureza da ciência e fomentar discussões sobre práticas e valores científicos. Nesse sentido, ressaltamos que nosso objetivo pedagógico não é apenas instrumentalizar os alunos a usar a teoria quântica contemporânea; mas, também, viabilizar uma melhor compreensão sobre a própria cultura científica.

Por fim, a apresentação de perguntas ao final de cada trecho é baseada em uma concepção dialógica de ensino, lastreada na teoria socio-histórica de Vygotsky [15]. Ao invés de apresentar apenas um texto que o aluno lê de forma passiva, a proposta do material é viabilizar um "diálogo". Esse diálogo pode ser fomentado de forma concreta, na sala de aula, entre os alunos ou entre os alunos e o professor, ou, em um sentido abstrato, um diálogo entre o aluno e o texto. Após cada trecho de artigo original, o aluno é convidado a "responder", a se expressar, a materializar suas reflexões a partir do que foi estudado, podendo conectar-se com outros textos e conhecimentos prévios. As perguntas ao final de cada trecho fomentam a relação do aluno com a leitura, permitindo um aprofundamento e maior compreensão. As perguntas podem, então, ser retomadas pelo professor e discutidas em sala de aula.

\section{Uma unidade didática construída com trechos de artigos seminais da física quântica sobre a dualidade onda-partícula}

O presente texto possui sete seções. Na primeira seção, apresentamos uma breve descrição do contexto científico no início do século XX. Na segunda, apresentamos o problema da dualidade onda-partícula nos trabalhos de Albert Einstein. Na terceira, apresentamos o problema da dualidade onda-partícula nos trabalhos de Louis de Broglie. Na quarta, apresentamos o problema da dualidade onda-partícula nos trabalhos de Erwin Schrödinger. Na quinta, apresentamos o problema da dualidade onda-partícula nos trabalhos de Max Born. Na sexta, apresentamos o problema da dualidade ondapartícula nos trabalhos de Niels Bohr. Na sétima e última seção, apresentamos o problema da dualidade onda-partícula em trabalhos posteriores à proposta de Niels Bohr. Ao final do artigo, incluímos dois apêndices; no apêndice $\mathrm{A}$, apresentamos uma reprodução didática da derivação original de Einstein (1905) e, no apêndice $\mathrm{B}$, demonstramos a equivalência entre o Princípio de Maupertuis e de Fermat no contexto não-relativístico.

\subsection{Uma breve descrição do contexto científico inicial}

No início do século XX, a física dispunha de uma série de teorias bem-sucedidas para a explicação do mundo natural. Em especial, a mecânica já havia sido estabelecida no formalismo newtoniano e hamiltoniano. Maxwell já havia estabelecido sua teoria sobre o eletromagnetismo. E a termodinâmica e mecânica estatística estavam começando a florescer após os trabalhos de Ludwig Boltzmann. Essas teorias seriam, posteriormente, classificadas como o que chamamos de física clássica.

No final do século XIX e início do século XX, o processo de urbanização (e o consequente processo de iluminação das cidades) motivou muitos cientistas e se dedicarem ao desenvolvimento de métodos objetivos e reprodutíveis de intensidade luminosa. Tal busca daria origem ao conceito de corpo negro (corpo em que toda radiação incidente é absorvida e emitida).

Para descrever esse fenômeno, teoricamente, era necessário mobilizar simultaneamente a termodinâmica e a teoria eletromagnética visto que os elementos constituintes do corpo negro (como cargas oscilando) deveriam estar em equilíbrio termodinâmico com a radiação. $\mathrm{O}$ problema é que a descrição clássica desse equilíbrio (chamada, hoje, de modelo de Rayleigh-Jeans) conduzia a uma função de densidade de energia que, apesar de descrever bem o comportamento de radiações de baixa frequência em alta temperatura, tende ao infinito para grandes frequências (o que ficou conhecido como catástrofe do ultravioleta). Outra proposta, inspirada na mecânica estatística, havia sido elaborada por Wien 
e era capaz de descrever bem a densidade de energia associada a radiações de grande frequência e baixa temperatura; mas não a radiações de baixa frequência. Em 1900, Max Planck chegou a uma função que descreve de forma adequada a radiação de corpo negro em todo o espectro. Tal solução foi encontrada, primeiramente, através de uma interpolação dos dois modelos anteriores.

Até esse momento, não havia nenhuma discussão essencial sobre a necessidade de rever conceitos fundamentais da física. A mecânica era capaz de descrever com grande precisão a trajetória de partículas (corpos materiais cujas dimensões são desprezíveis em comparação com a trajetória realizada). A termodinâmica e a mecânica estatística descreviam o comportamento macroscópico da matéria (propriedades termodinâmicas) conectando-as com o comportamento dos constituintes microscópicos. E a teoria eletromagnética de Maxwell descrevia o comportamento de campos contínuos (campo elétrico e magnético) que, por sua vez, explicavam a natureza ondulatória da luz, sendo capaz de descrever fenômenos da ótica física (refração, difração, interferência). A ótica geométrica, que trata de raios retilíneos de luz (e não de ondas), podia ser entendida como um caso limite da ótica física em que as dimensões dos fenômenos estudados ultrapassavam em algumas ordens de grandeza o comprimento da luz incidente. O quadro da descrição da natureza parecia estar completo. Em especial, podemos ressaltar que tal quadro envolvia a classificação dos entes físicos em dois grupos. O primeiro grupo engloba as partículas, corpos materiais, bem localizados no espaço e, portanto, com trajetória bem definida. O segundo grupo envolve os campos, sistemas contínuos, que se distribuem pelo espaço, que podem dar origens às ondas, as quais não possuem uma trajetória bem definida e associam-se a fenômenos típicos como interferência e difração [16.

Conforme estudaremos, a partir de 1905, entretanto, uma série de cientistas começou a sinalizar que o esquema clássico da física era incapaz de descrever fenômenos na escala atômica. Nas próximas seções, em especial, vamos analisar alguns trechos de artigos seminais do século XX que colocaram a descrição da realidade em termos de partículas e ondas sob suspeição. Em especial, os diferentes estudos que analisaremos levaram ao reconhecimento de que os sistemas quânticos podem apresentar uma natureza dual, ou seja, eles apresentam, na mesma escala, tanto características corpusculares quanto ondulatórias [17]. A expressão "na mesma escala" é extremamente importante, pois tratar a água macroscopicamente como um fluido contínuo, enquanto reconhecemos microscopicamente que ela é formada por moléculas corpusculares e localizadas, não é uma visão dual. Apenas quando um determinado sistema físico pode ser descrito tanto por um quadro ondulatório quanto por um quadro corpuscular na mesma escala é que estamos diante de um sistema dual [17. Tendo isso em mente, ao longo do roteiro, vamos discutir quais propostas eram duais ou não, segundo essa definição ${ }^{1}$

\subsection{O problema da dualidade onda-partícula nos trabalhos de Albert Einstein}

No século XX, Einstein [18, p. 86] apresentou uma discussão contestando a natureza ondulatória da luz no trabalho intitulado "Sobre uma Ponto de Vista Heurístico sobre a Emissão e Transformação da Luz". $\mathrm{Na}$ introdução do artigo, Einstein apresenta sua problematização sobre o assunto:

Uma profunda distinção formal existe entre os conceitos teóricos que físicos formaram sobre gases e outros corpos ponderáveis e a teoria de Maxwell dos processos eletromagnéticos no chamado espaço vazio. Enquanto consideramos o estado de um corpo completamente determinado pelas posições e velocidades de um número muito grande, ainda que finito, de átomos $e$ elétrons, fazemos uso de funções espaciais contínuas para descrever o estado eletromagnético de um dado volume; e um número finito de parâmetros não pode ser considerado suficiente para a determinação completa deste estado. De acordo com a teoria de Maxwel, energia deve ser considerada uma função espacial contínua no caso de todos os fenômenos puramente eletromagnéticos, incluindo a luz, enquanto a energia de um objeto ponderável deveria, de acordo com as concepções presentes dos físicos, ser representada como uma soma sobre os átomos e elétrons. A energia de um corpo ponderável não pode ser subdividida arbitrariamente em muitas partes ou em partes pequenas, enquanto a energia de um feixe de luz produzido por uma fonte pontual (de acordo com a teoria de Maxwell ou, mais genericamente, de acordo, com qualquer teoria ondulatória) é continuamente espalhada em um volume cada vez maior. (...) A teoria ondulatória da luz, que opera com funções espaciais contínuas, tem trabalhado bem com a representação de fenômenos puramente óticos, e provavelmente nunca irá ser substituída por nenhuma outra teoria. Deveria ser mantido em mente, entretanto, que observações óticas se referem a médias temporais ao invés de valores instantâneos. Apesar da confirmação experimental completa da teoria como é aplicada para difração, reflexão, refração, dispersão, etc, é ainda

\footnotetext{
1 Ressaltamos, entretanto, que, usando-se outras definições de dualidade, é possível chegar em classificações diferentes.
} 
concebivel que a teoria da luz, que opera com funções espaciais contínuas, leve a contradições com experiências quando aplicada a fenômenos de emissão e transformação da luz. (...) Parece para mim que as observações associadas com a radiação de corpo negro, a fluorescência, a produção de raios catódicos por luz ultravioleta e outros fenômenos relacionados com a emissão e transformação da luz são mais prontamente compreendidos se alguém assume que a energia da luz é descontinuamente distribuída no espaço. De acordo com a hipótese a ser assumida aqui, a energia de um raio de luz se espalhando de uma fonte pontual não é continuamente distribuída por um espaço cada vez maior mas consiste de um número finitos de quanta de energia que estão localizados em pontos do espaço, que se movem sem se dividir, e que podem ser emitidos e absorvidos em unidades completas [18, p. 86].

Perguntas sobre o artigo de Einstein (1905)

(a) O que significa a palavra heurístico, no título do artigo de Einstein?

(b) Qual é o problema na descrição da realidade que Einstein aponta?

(c) Faça uma tabela comparando características de corpos ponderáveis e características de fenômenos eletromagnéticos

(d) Qual é o argumento de Einstein sobre o fato de a teoria eletromagnética fazer previsões corretas de fenômenos óticos?

(e) Qual é a proposição de Einstein sobre a natureza da luz?

(f) Quais fenômenos são melhor entendidos com essa proposição?

(g) Quando os quanta são emitidos, eles se propagam como ondas ou partículas?

(h) Qual a implicação dessa visão para a teoria eletromagnética? Em que medida ela se opõe às teorias anteriores?

(i) Essa é uma visão dual?

Comentários: Conforme comentamos na seção 3.1 (contexto científico), a física de 1905 tratava de dois tipos distintos de entes, corpos ponderáveis (partículas, as quais são localizadas no espaço) e campos contínuos (distribuídos pelo espaço), responsáveis por mediar as interações entre essas partículas. O problema de determinação da função que descreve o espectro de corpo negro, até então, não implicava nenhuma ruptura com tal esquema ontológico. As propostas de Planck tanto em 1900 [19] quanto em 1901 [20] não apresentam nenhuma proposta clara de quantização da radiação eletromagnética; mas da distribuição de energia nos osciladores que fazem parte da constituição da matéria.
O primeiro trabalho a apontar uma necessidade na revisão de tal esquema é o trabalho de Einstein, em 1905, no qual ele claramente afirma que a radiação é emitida e se propaga de forma localizada (portanto, tendo comportamento corpuscular). Einstein havia se dedicado, desde 1900, a estudar termodinâmica e teoria estatística, permitindo-lhe dar contribuições equiparáveis aos trabalhos de Gibbs e Boltzmann [21]. Foi com essa concepção de termodinâmica e de mecânica estatística que Einstein avançou no estudo da radiação de corpo negro. Ele parecia saber, entretanto, que seu pensamento era revolucionário, pois vários elementos do seu texto tentam apontar o caráter hipotético ou conjectural de sua proposta, como o termo "heurístico" (que remete à ideia de descoberta - eureka - algo sem prova formal). O grande problema que a proposta de radiação quantizada de Einstein enfrenta é a explicação dos fenômenos da ótica física (como interferência e difração), que são amplamente explicados pela teoria eletromagnética. A solução provisória de Einstein é sugerir que a teoria eletromagnética lida apenas com médias, como se tais fenômenos fossem efeito de um conjunto de quanta. Assim, a teoria eletromagnética seria apenas uma aproximação da descrição dos fenômenos óticos. Por outro lado, Einstein conseguia explicar, com certa simplicidade, fenômenos de emissão e transformação da luz. Não se deve imaginar, entretanto, que outras teorias não existiam. Pelo contrário, a "hipótese do gatilho" de Lenard continuou amplamente aceita mesmo depois da publicação do texto do Einstein [17]. Por conceber os quanta como porções localizadas e propor que os fenômenos ondulatórios são propriedades de um conjunto, não se pode entender a proposta de Einstein em 1905 como dual. Louis de Broglie, entretanto, considerava que o trabalho de 1905 de Einstein era dual [17], pois ao mesmo tempo que ele falava dos quanta como corpúsculos, ele lhes atribuía frequência (uma propriedade ondulatória). Adotando, entretanto, a definição de dualidade que apresentamos no início desse material didático, pode-se entender que a proposição de Einstein não era dual, uma vez que atribui somente a ontologia corpuscular ao quantum - assumindo que propriedades ondulatórias somente são possíveis em outra escala.

Com relação à estrutura matemática do artigo de Einstein em 1905, alguns comentários são importantes. Enquanto Planck havia quantizado a energia dos osciladores, podendo essa ser múltipla da frequência $\nu$ $(E=h \nu)$, Einstein não parte da equação de Planck (mas de Wien) e usa um modelo de gás diluídd² (com o qual já estava muito familiarizado devido seus estudos de termodinâmica e mecânica estatística) para chegar em

$$
E=\frac{R \beta \nu}{N}
$$

\footnotetext{
$\overline{2}$ No apêndice $\mathrm{A}$, fazemos uma reprodução didática da derivação da equação $E=\left(\frac{R \beta}{N}\right) \nu$.
} 
em que $\frac{R \beta}{N}$ é numericamente idêntica à constante de Planck $h$. Einstein, entretanto, não afirma isso em seu artigo. Em 1906, Einstein [18, p. 192] reconhece que, no seu artigo anterior, ele imaginava que sua proposta era incompatível com o modelo de Planck.

Em 1909, uma nova visão sobre a natureza da luz foi apresentada por Einstein. Em um artigo intitulado "Sobre o estado presente do problema da radiação", Einstein [18, p. 357] determina a expressão do valor médio das flutuações da energia $\epsilon^{2}$ da radiação presente em um volume $v$, descrita pela fórmula de radiação de Planck da radiação de corpo negro (e não mais de Wien) e obtém a seguinte expressão

$$
\epsilon^{2}=\frac{R}{N k}\left(\nu h \eta_{0}+\frac{c^{3}}{8 \pi \nu^{2} d \nu} \frac{\eta_{0}^{2}}{v}\right)
$$

Einstein observa que o segundo termo entre parênteses pode ser obtido diretamente da lei de radiação de Rayleigh (compatível com uma concepção ondulatória de radiação eletromagnética), enquanto o primeiro termo não pode ser derivado de tal concepção. Em um segundo trabalho, no mesmo ano, Einstein explica:

\begin{abstract}
Imagino mais ou menos cada um desses pontos singulares como estando rodeado por um campo de força que tem essencialmente o caráter de uma onda plana e cuja amplitude diminui com a distância ao ponto singular. Se muitas dessas singularidades estão presentes em intervalos que são pequenos em comparação com as dimensões do campo de força de um ponto singular, então tais campos de força se sobreporão, e sua totalidade produzirá um campo de força ondulatório que pode diferir apenas ligeiramente de um campo ondulatório conforme definido pela atual teoria eletromagnética da luz. Estou certo de que não precisa ser particularmente enfatizado que nenhuma importância deve ser atribuída a tal quadro, uma vez que não tenha conduzido a uma teoria exata. Tudo o que eu queria é indicar brevemente com sua ajuda que as duas propriedades estruturais (a estrutura ondulatória e a estrutura quântica) exibidas simultaneamente pela radiação de acordo com a fórmula de Planck não devem ser consideradas como mutuamente incompativeis [18, p. 394].
\end{abstract}

Perguntas sobre o artigo de Einstein (1909)

(a) Qual a visão sobre a natureza apresentada por Einstein?

(b) Como essa visão dialoga com a do artigo de 1905? Em que medida ela se opõe às teorias anteriores?

(c) A visão de Einstein é dual?

(d) Einstein conseguiu apresentar uma visão organizada e consistente sobre a natureza da luz?
Comentários: O artigo "Sobre o estado presente do problema da radiação" é o primeiro artigo verdadeiramente dual, pois nele propriedades corpusculares e ondulatórias são auferidas ao mesmo ente na mesma escala [17. No artigo de 1905, o quantum era uma "partícula" e o comportamento ondulatório poderia ser um efeito estatístico. Em 1909, diferentemente, nos dois textos mencionados, Einstein concebe a radiação como possuindo estruturalmente corpúsculos e campos.

Usando apenas argumentos dimensionais, Einstein interpreta o primeiro termo da equação (1) como estando relacionado à flutuação de energia de uma radiação corpuscular e o segundo termo como a uma radiação ondulatória. Nesse sentido, Einstein avança em relação à sua primeira proposta. Como ele mesmo afirma, entretanto, tal proposta é apenas conjectural - não há ainda uma apresentação formal capaz de descrever a natureza dual de tal radiação.

\subsection{O problema da dualidade onda-partícula nos trabalhos de Louis de Broglie}

Em 1922, de Broglie [22, p. 422] apresentou um estudo teórico sobre a natureza da luz:

O objetivo deste trabalho é estabelecer um certo número de resultados conhecidos da teoria da radiação por razões que se apoiam unicamente na termodinâmica, na teoria cinética e aquela dos quanta sem nenhuma intervenção do eletromagnetismo. (...) A hipótese adotada aqui é aquela dos quanta de luz. A radiação negra em equilíbrio a uma temperatura $T$ é considerada como um gás formado de átomos de luz de energia $W=h \nu$. Nós negligenciaremos nesse ensaio as moléculas de luz com 2,3,...n átomos $h \nu$, isto é, deveremos chegar a lei de de radiação de Wien, pois, do ponto de vista do quanta de luz, a forma de Wien deriva da equação completa de Planck quando se negligencia a associação de átomos. (...) A massa de átomos de luz é suposta, conforme as fórmulas da mecânica relativística, igual a $\frac{h \nu}{c^{2}}$, quociente da energia pelo quadrado da velocidade da luz. A quantidade de movimento é $\frac{h \nu}{c}=\frac{W}{c}$ [22, p. 422].

Perguntas sobre o artigo escrito por de Broglie (1922):

(a) Por que de Broglie se preocupa em não usar a teoria eletromagnética?

(b) Qual a visão sobre a luz de de Broglie?

(c) A visão dele é uma visão dual?

(d) Quais propriedades um quantum pode ter? Quais problemas isso traz em relação às teorias já estabelecidas?

(e) Para de Broglie chegar à Lei de Wien, qual hipótese ele usa? 
(f) De Broglie conecta que propriedade corpuscular da luz com a frequência?

(g) Em que medida ele se opõe às teorias anteriores?

Comentários: Louis de Broglie apresenta uma proposta que leva a ideia original de Einstein às últimas consequências. A visão de Louis de Broglie é corpuscular (portanto não é dual) e, de acordo com ela, quanta possuem massa. Ressaltamos que, embora ainda haja estudos que investiguem a possibilidade de luz ter massa 23], tal ideia não é aceita na concepção contemporânea da física. Para de Broglie, no repouso, todos quanta são idênticos, o que os distingue é a diferente velocidade com que são observados. Assim, a frequência de um quantum está relacionada com sua energia e sua velocidade [7. Para chegar à lei de Wien, é necessário supor um gás de quanta em que a interação entre os quanta é desprezível - o que corresponde ao modelo de gás diluído de Einstein. Louis de Broglie mostra que, ao considerar a possibilidade de formação de moléculas de quanta, chega-se à expressão de Planck para radiação [17].

Nesse sentido, a proposta de Louis de Broglie de 1922 contraria a teoria eletromagnética não somente porque considera a radiação quantizada, mas porque permite que os quanta se movam com diferentes velocidades no vácuo, o que demandaria correções substanciais nas Equações de Maxwell 23. De acordo com as equações de Maxwell, a velocidade da luz no vácuo é $c=1 / \sqrt{\mu_{o} \epsilon_{0}}$. Por outro lado, de Broglie obtém uma expressão que relaciona a velocidade da luz no vácuo com sua frequência, sendo sempre menor do que c, mais especificamente, para de Broglie, a velocidade da luz com frequência $\nu$ é dado por: $v=\sqrt{c^{2}-m_{0}^{2} c^{6} / h^{2} \nu^{2}}$ [7]. Nesse contexto, o segundo postulado da Teoria da Relatividade também precisa ser reinterpretado, de forma que $c$ não é a velocidade da luz, mas uma velocidade limite para corpos com massa.

Em 1923, de Broglie [24 deu um passo adiante na descrição de sua teoria:

Consideremos um móvel material de massa de repouso $m_{0}$ se movendo em relação a um observador fixo com velocidade $v=$ $\beta c(\beta<1)$. De acordo com o princípio da inércia da energia, ela deve possuir uma energia interna igual à $m_{0} c^{2}$. Por outro lado, o princípio dos quanta conduz a atribuir esta energia interna a um fenômeno periódico simples de frequência $\nu_{0}$ tal que

$$
h \nu_{0}=m_{0} c^{2}
$$

c é sempre a velocidade limite da teoria da relatividade e h é a constante de Planck.

Para um observador fixo, corresponderá à energia total do móvel uma frequência $\nu=$ $\frac{m_{0} c^{2}}{h \sqrt{1}-\beta^{2}}$. Mas, se um observador fixo observa o fenômeno periódico interno do móvel, ele o verá lento e lhe atribuirá uma frequência $\nu_{1}=\nu_{0} \sqrt{1-\beta^{2}}$ [24, p. 507].

(...)

Vamos primeiro aplicar isso a um átomo de luz. Eu mostrei em outro artigo que o átomo de luz deve ser considerado como um móvel de massa muito pequena $\left(<10^{-50} \mathrm{gr}\right)$ se movendo com uma velocidade muito sensivelmente igual à c (ainda que levemente inferior). Chegamos, portanto, no seguinte enunciado: $<<O$ átomo de luz equivalente, em razão de sua energia total, a uma radiação de frequência $\nu$ é o assento de um fenômeno periódico interno que, visto por um observador fixo, tem em cada ponto do espaço a mesma fase que uma onda de frequência $\nu$ que se propaga na mesma direção com uma velocidade sensivelmente igual (ainda que ligeiramente superior) à constante dita velocidade da luz [24, p. 508].

Perguntas sobre o artigo de Louis de Broglie em 1923:

(a) Sobre que objeto o artigo de Louis de Broglie começa falando?

(b) Sua teoria era uma teoria somente sobre a radiação?

(c) Sua proposta é relativística ou não relativística?

(d) Qual a importância do artigo escrito por de Broglie de 1922 para o de 1923 ?

(e) Como os dois artigos dialogam? O que permanece e o que muda ou avança em 1923 em relação a 1922?

(f) A concepção defendida por de Broglie era dual?

(g) Como era a concepção de luz proposta por de Broglie?

(h) Quais características da onda de que de Broglie fala?

(i) Como essa visão avança em relação ao que Einstein havia proposto?

Em 1924, Louis de Broglie [25] apresentou um artigo, em inglês, sintetizando e organizando seus estudos teóricos sobre a radiação e a matéria. Esse artigo é extremamente relevante, pois nele os principais resultados da proposta de Louis de Broglie aparecem de forma sistemática e precisa. Por isso, vamos apresentar alguns trechos essenciais desse trabalho:

Eu assumirei no presente artigo a existência real dos quanta de luz, e tentarei mostrar como é possível reconciliar com ela as fortes evidências experimentais baseadas na teoria ondulatória [25, p. 446].

Nosso teorema é o seguinte: - "Se, no início, o fenômeno interno de corpo em movimento está em fase com a onda, essa harmonia da fase deve sempre persistir [25] p. 449]. 
Somos, então, inclinados a admitir que qualquer corpo em movimento deve ser acompanhado de uma onda e que é impossível dissociar o movimento do corpo e a propagação da onda [25, p. 450].

Talvez um novo eletromagnetismo nos dará as leis dessa propagação complicada, mas parece que sabemos de antemão o resultado final: "Os raios da onda de fase são idênticos aos caminhos que são dinamicamente possiveis [25, p. 451].

$\underline{\text { Perguntas sobre o trabalho de Louis de Broglie em } 1924}$

(a) Qual é a concepção sobre a natureza da radiação proposta por Louis de Broglie?

(b) A sua proposta de associar uma onda a um ente material é, segundo de Broglie, válida para algum tipo específico de partícula?

(c) Qual nova teoria seria necessária para de Broglie? Por que isso seria necessário?

(d) De Broglie fala de "raios da onda" e "caminhos dinamicamente possíveis". Quais duas áreas da física, de Broglie está buscando sintetiza com essa passagem?

Comentários: O trabalho de 1923 escrito por de Broglie fala de corpos materiais com massa $m_{0}$. Uma vez que, em 1922, ele havia proposto a ideia de quanta com massa, a proposta de Louis de Broglie é válida para todos os corpos. Isso aparece, novamente, em 1924 quando ele associa uma onda a todo "corpo material em movimento". A articulação teórica de Louis de Broglie em 1923 e 1924 é uma proposta de descrição dual para todo sistema físico (observe-se que ele usa, em 1923, a expressão de Einstein $E=h \nu$ para descrever a energia de um corpo material qualquer com massa $m_{0}$ ). Devese chamar atenção ao fato, também, de que de Broglie usa a noção de massa relativística, a qual é bastante problematizada na literatura 26.

De qualquer forma, de Broglie parte de uma descrição relativística e dual, associando a todo corpo material um fenômeno ondulatório - o que, em grande medida, resgata a ideia dos artigos de Einstein em 1909. As ondas encontradas por de Broglie, entretanto, possuem velocidade acima da velocidade da luz e, de acordo com a Teoria Especial da Relatividade, não podem transportar energia. De Broglie consegue mostrar que, na verdade, a todo corpo material deve-se associar não uma onda, mas um grupo de ondas, em que a velocidade de grupo é idêntica à velocidade da partícula enquanto a velocidade de fase é superior à da luz.

Em 1924, de Broglie argumenta que tal visão dual permite a síntese de duas áreas da física: a ótica geométrica e a mecânica. No contexto da ótica geométrica, podese tratar a propagação da luz como um conjunto de raios, e o caminho da luz pode ser descrito pelo Princípio de Minimização de Fermat. No caso da mecânica, as trajetórias dinamicamente possíveis das partículas podem ser obtidas pelo Princípio de Mínima Ação, ou, quando só há campos conservativos, pelo Princípio de Maupertuis. Louis de Broglie mostra, em 1924, que o Princípio de Maupertuis para partícula é exatamente idêntico à expressão do Princípio de Fermat aplicado à onda associada à partícula. Ou seja, pode-se tratar um ente físico tanto pela mecânica do ponto material quanto pela "ótica" das ondas associadas.

Em uma abordagem relativística, as propriedades dinâmicas de uma partícula podem ser descritas em um quadrivetor momento-energia:

$$
\boldsymbol{I}=\left(\frac{E}{c}, p_{x}, p_{y}, p_{z}\right)
$$

Em que $E, p_{x}, p_{y}$ e $p_{z}$ são a energia e o momento na direção $x, y$ e $z$, respectivamente e $c$ é a velocidade da luz ${ }^{3}$ Da mesma forma, uma onda pode ser caracterizada por sua frequência angular $\omega$ e por seus números de onda $k_{x}, k_{y}$ e $k_{z}$ :

$$
\Psi=A \cos \left(w t-k_{x} x-k_{y} y-k_{z} z\right)
$$

Louis de Broglie, propôs, então caracterizar tal onda por um quadrivetor de Onda:

$$
\boldsymbol{O}=\left(\frac{\omega}{c}, k_{x}, k_{y}, k_{z}\right)
$$

Se pensarmos que $\boldsymbol{I}$ representa o quadrivetor momento-energia de uma partícula e $\boldsymbol{O}$ sua onda associada, pela relação de Einstein $(E=h \nu=\hbar \omega)$, temos a relação entre a primeira componente dos dois quadrivetores. Considerando que, na Teoria da Relatividade, encontramos relações entre intervalos espaçotemporais (e, portanto, não é possível tratar intervalos temporais dissociados de espaciais), de Broglie propõe que a relação fornecida por Einstein indica, na verdade, a relação entre os dois vetores:

$$
\boldsymbol{I}=\hbar \boldsymbol{O}
$$

Logo, as componentes do momento da partícula se relacionam com o comprimento de onda por meio da seguinte relação:

$$
p_{x}=\hbar k_{x}, p_{y}=\hbar k_{y}, p_{z}=\hbar k_{z}
$$

Portanto, pode-se relacionar o momento da partícula com o comprimento de onda da onda associada:

$$
\lambda=\frac{h}{p}
$$

O que ficou conhecido como comprimento de onda de de Broglie. Apresentamos, anteriormente, uma narrativa didática demonstrando essa relação de outra forma [7].

\footnotetext{
3 No artigo de Louis de Broglie, o autor escreve a componente referente à energia como a quarta componente do quadrivetor.
} 
É interessante notar que a expressão (9) não aparece explicitamente nos artigos de 1923 ou 1924 de Louis de Broglie, embora já pudesse ser derivada das equações apresentadas. Em seu discurso na premiação do Nobel, em 1929, entretanto, Louis de Broglie [27] enfatiza a importância da relação (9). Ademais, embora sua derivação original tenha sido realizada a partir de expressões relativísticas, em 1929 de Broglie enfatiza o que ele chama de aproximação não-relativística, isto é,

$$
\lambda=\frac{h}{m v}
$$

Assim como no caso relativístico, no discurso de 1929 , de Broglie [27] mostra que é possível usar a expressão (9) para mostrar a equivalência entre o Princípio de Fermat (da ótica) e o Princípio de Maupertuis (da mecânica). Como, no presente trabalho, nos comprometemos com a apresentação de uma discussão nãorelativística, no anexo 2, fazemos uma demonstração didática da equivalência do Princípio da Fermat e do Princípio de Maupertuis no contexto não relativístico, em consonância com a apresentação de Louis de Broglie em seu discurso do Nobel. Uma apresentação didática sobre essa equivalência na formulação relativística é apresentada em [28].

Para sintetizar a essência da visão de Louis de Broglie, trazemos ainda um citação em que o físico apresenta sua concepção sobre a natureza da matéria e da radiação: "O propósito da mecânica ondulatória é operar a síntese entre a dinâmica do ponto material e a teoria das ondas na forma de Fresnel" [29, p. 225]. Deve-se ter clareza que essa síntese implicava, para de Broglie, a existência de uma partícula e, principalmente, de uma onda material associada a ela. Para reforçar essa ideia, trazemos um trecho de um artigo publicado por de Broglie mais de quarenta anos depois de seu discurso do Nobel:

\begin{abstract}
Quando concebi as primeiras ideias básicas da mecânica das ondas em 1923-24, fui orientado pelo intuito de realizar uma síntese física real, válida para todas as partículas, da coexistência da onda e dos aspectos corpusculares que Einstein introduziu para os fótons em sua teoria dos quanta de luz em 1905. Eu não tinha nenhuma dúvida naquela época sobre a realidade física da onda e a localização da partícula na onda [30, p. 5].
\end{abstract}

Ressaltamos que, embora possa se considerar a visão de Louis de Broglie como dual, isso não significa que ela é consistente com a visão contemporânea. Sua visão originalmente lidava, por exemplo, com um conjunto de ondas que se propagam no espaço físico, enquanto as ondas que são usadas na física quântica estão em um espaço de configurações. Essa visão dualista de Louis de Broglie dá origem a algumas interpretações da física quântica que podem ser denominadas de dualistarealista [16.

\subsection{O problema da dualidade onda-partícula nos trabalhos de Erwin Schrödinger}

Se por um lado, Louis de Broglie apontou a possibilidade de síntese da ótica e da mecânica por meio da equivalência entre o Princípio de Maupertuis e o Princípio de Fermat, por outro, tal síntese já havia sido proposta por Hamilton, ainda que isso não fosse muito conhecido pela maioria dos físicos no início do século XX, como Schrödinger aponta:

Nada do que foi dito até então possui qualquer novidade. Tudo isso era muito melhor conhecido pelo próprio Hamilton do que por muitos físicos de hoje. De fato, a teoria da propagação da luz em um meio nãohomogêneo, desenvolvida por ele dez anos antes, se tornou, pela analogia impressionante que lhe ocorreu, o ponto de partida para suas teorias famosas em mecânica pura [31, p. 1052].

Nessa mesma citação, Schrödinger reconhece que Louis de Broglie havia redescoberto tal analogia no caso relativístico. Inspirado por essa concepção, Schrödinger avança na analogia de Hamilton:

A saída está apenas na possibilidade, já indicada acima, de atribuir ao princípio de Hamilton, também, a operação de um mecanismo de onda em que os processos mecânicos pontuais são essencialmente baseados, assim como há muito tempo se acostumava a fazer no caso de fenômenos relacionados com luz e do princípio de Fermat que os rege. É certo que o caminho individual de um ponto de massa perde seu significado físico adequado e se torna tão fictício quanto o raio de luz individual isolado. A essência da teoria, o princípio mínimo, no entanto, permanece não apenas intacto, mas revela seu significado verdadeiro e simples apenas sob o aspecto ondulatório, como já se explicou. Estritamente falando, a nova teoria na verdade não é nova, é um desenvolvimento completamente orgânico, pode-se quase ficar tentado a dizer uma exposição mais elaborada, da velha teoria 32 .

Perguntas iniciais sobre a proposição de Schrödinger:

(a) Qual teoria é o ponto de partida de Schrödinger?

(b) Como se pode justificar conceitualmente o princípio de Fermat (da ótica geométrica), que trata de raios de luz, com a concepção ondulatória da ótica física?

(c) Em que sentido a proposição de uma visão ondulatória para matéria completa ou torna mais elaborada a visão de Hamilton? 
A apresentação de sua concepção ondulatória, foi realizada por Schrödinger em uma série de trabalhos publicados a partir de 1926 33. Vamos apresentar, na sequência, uma série de trechos nos quais Schrödinger apresenta de forma explícita sua visão sobre a natureza da matéria e da radiação. Primeiramente, vejamos como Schrödinger descreve a luz:

\begin{abstract}
É concebível que na transição de energia de um para outro modo normal de vibração, alguma coisa - quero dizer, a onda de luzcom frequência associada a cada diferença de frequência, deve aparecer. Precisa-se apenas imaginar que a onda de luz é causalmente relacionada aos batimentos, os quais necessariamente aparecem em cada ponto do espaço durante a transição, e que a frequência da luz é definida pelo número de vezes por segundo que a intensidade máxima do processo de batimento repete a si mesmo [33, p. 15].
\end{abstract}

Perguntas sobre o primeiro artigo de Schrödinger acerca do problema de auto-valor

(a) Qual a visão de Schrödinger sobre a natureza da luz?

(b) Como essa visão se aproxima ou se afasta das visões de Einstein e de Broglie? Schrödinger nega visões anteriores?

(c) Há alguma menção à Teoria da Relatividade Restrita?

(d) Ele atribui algum papel real à função de onda?

No seu segundo artigo de 1926, Schrödinger aprofunda a relação entre a mecânica de Hamilton-Jacobi e mecânica ondulatória. A partir dessa análise, Schrödinger apresenta sua visão sobre processos mecânicos:

\begin{abstract}
O verdadeiro processo mecânico é compreendido ou representado de forma adequada pelos processos ondulatórios no espaço-q, e não pelo movimento de pontos de imagem neste espaço. O estudo do movimento de pontos de imagem, que é o objeto da mecânica clássica, é apenas um tratamento aproximado e tem apenas tanta justificação quanto óptica geométrica ou de "raios" em comparação com os verdadeiros processos óticos [33, p. 25].
\end{abstract}

$\underline{\text { Perguntas sobre o segundo artigo de Schrödinger }}$ sobre o problema de auto-valor

(a) Qual a visão de Schrödinger sobre os processos mecânicos em geral?

(b) Essa visão é dual?

(c) Essa visão nega as visões anteriores?
Na seção 7 do quarto artigo sobre mecânica quântica como problema de autovalor, Schrödinger discute o significado físico da função de onda:

$\psi \bar{\psi}$ é uma espécie de função-peso no espaço de configuração do sistema. A configuração ondulatório-mecânica do sistema é uma sobreposição de muitas, estritamente falando de todas as configurações ponto-mecânicas cineticamente possíveis. Assim, cada configuração ponto-mecânica contribui para a verdadeira configuração ondulatório-mecânica com um certo peso, que é dado precisamente por $\psi \bar{\psi}$ [33, p. 120].

Por fim, com sua visão ondulatória, Schrödinger foi capaz de explicar fenômenos "corpusculares" como o Efeito Compton:

\section{As leis da direção e da frequência do Efeito Compton são completamente equivalentes à afirmação que o par de ondas de luz e o par de ondas- $\psi$ relacionadas à relação de Bragg para reflexão de primeira ordem (generali- zada para um cristal em movimento) para a rede espacial [33, p. 129].}

Pergunta final sobre os trabalhos de Schrödinger:

(a) Pode-se dizer que o programa de pesquisa iniciado por Schrödinger avança na mesma direção apontada por Einstein em 1905? Ou por de Broglie? Em que medida eles se aproximam e em que medida eles se afastam?

Comentários: Como podemos observar dos trechos transcritos, Schrödinger entendia sua proposta como uma elaboração da analogia original de Hamilton. Isso pode ser compreendido da seguinte forma. $\mathrm{Na}$ ótica física, tratamos a luz como uma onda eletromagnética. Quando essa passa por uma fenda de tamanho da ordem de grandeza de seu comprimento de onda, por exemplo, sua natureza ondulatória fica explícita, de forma que efeitos como interferência e difração são perceptíveis. Por outro lado, na ótica geométrica, tratamos a trajetória da luz com o conceito de raio de luz. Nesse caso, a trajetória de tais raios pode ser obtida pelo Princípio de Fermat, o qual consegue prever, por exemplo, corretamente a Lei de Snell da refração. Em um primeiro momento, essas duas descrições poderiam parecer contraditórias ou excludentes; mas, como reconhece Schrödinger 32 , é justamente a visão ondulatória que explica e justifica a descrição dos raios de luz. Quando reconhecemos que o raio é só um artifício matemático, o qual é caracterizado por apontar na direção normal à frente de onda (Princípio de Huygens), podemos facilmente explicar a mudança de direção do raio quando a luz muda de meio. Nesse caso, a diferença de velocidade nos diferentes meios faz com que a frente de onda mude de formato, e o raio normal, claramente, mudará de direção. 
Assim, a descrição dos raios de luz da ótica geométrica e o Princípio de Fermat são artifícios matemáticos que expressam o que está acontecendo com as ondas de luz.

Da mesma forma, como apontado por Schrödinger 31, o Princípio de Mínima Ação de Hamilton, que fornece a trajetória dinamicamente possível de uma partícula material, foi inspirado no Princípio de Fermat. O que Schrödinger se propôs a fazer foi completar a analogia: da mesma forma que o raio de luz e o Princípio de Fermat são artifícios matemáticos que expressam o que ocorre com a onda de luz, o princípio de mínima ação e a trajetória de uma partícula são abstrações de um fenômeno essencialmente ondulatório. Assim, para Schrödinger, noções como partículas e trajetórias são apenas abstrações e não correspondem ao fenômeno físico real. Ademais, da mesma forma que não podemos usar a ótica geométrica para tratar o comportamento da luz quando essa passa por uma fenda com largura da ordem de grandeza do seu comprimento de onda, devendo recorrer ao seu caráter ondulatório, Schrödinger argumenta que, quando estamos tratando de sistemas da mesma ordem de grandeza do comprimento de onda do elétron, por exemplo, não devemos o tratar por sua imagem como partícula, mas por meio de sua descrição ondulatória. Portanto, a função de onda $\psi$ de Schrödinger, para ele, representa a descrição do verdadeiro fenômeno físico.

Tal visão enfrenta dificuldades, entretanto. Posteriormente, Schrödinger percebeu que tal onda se propaga no espaço de configurações e não no espaço tridimensional. Dessa forma, o fenômeno em nosso espaço seria apenas uma projeção do fenômeno no espaço de configuração. $\mathrm{Na}$ última comunicação, o entendimento de Schrödinger já havia avançado no sentido de perceber que essas ondas possuem uma "realidade" bem distinta das ondas que estamos acostumados - tratando-se de "funções peso" no espaço de configuração.

A visão de Schrödinger, assim, não é propriamente dual, mas puramente ondulatória. Isso não significa que essa seja uma onda no sentido usual, mas, simplesmente, significa que, para Schrödinger, um corpúsculo seria apenas um epifenômeno, uma manifestação particular de um ente cuja natureza é contínua - a função de onda. Isso fica claro no seu tratamento do Efeito Compton.

Uma das grandes contribuições de Schrödinger foi desenvolver não somente essa visão ondulatória, mas derivar a equação de onda que descreve tais sistemas a equação de Schrödinger - talvez uma das equações mais famosas da física quântica. Vale-se ressaltar que, analisando-se diversos cadernos e correspondências de Schrödinger, é possível reconhecer que o físico austríaco buscou desde o início uma equação de onda relativística, cuja solução estaria de acordo com as ondas de de Broglie 34 36. De fato, Schrödinger havia encontrado inicialmente tal equação, mas ela não fornecia satisfatoriamente o espectro de emissão do Hidrogênio 31 o que teria então o direcionado para um programa não-relativístico, que acabou sendo publicado em sua derivação de 19264 4 Por isso, os trechos que observamos não tratam de física relativística, ainda que Schrödinger se valha de noções da proposta de Louis de Broglie.

\subsection{O problema da dualidade onda-partícula nos trabalhos de Max Born}

Ainda no ano de 1926, Max Born [37] apresentou profundas e importantes reflexões sobre o desenvolvimento da física quântica:

De acordo com Schrödinger, o átomo no n-ésimo estado quântico é uma vibração de uma função de estado de frequência fixa $W_{n}^{0} / h$ espalhado por todo espaço. Em particular, um elétron se movendo em uma linha reta é um fenômeno vibratório que corresponde a uma onda plana. Quando essas duas ondas interagem, uma vibração complicada aparece. Entretanto, pode-se ver imediatamente que se pode determiná-la através de seu comportamento assintótico no infinito. De fato, não se tem nada além de um problema de difração no qual uma onda plana vindoura é refratada ou espalhada por um átomo [37, p. 2].

Se traduzimos este resultado em termos de partículas, apenas uma interpretação é possível. $\Phi_{n, m}(\alpha, \beta, \gamma)$ dá probabilidade do elétron, chegando da direção z, ser jogado na direção designada pelos ângulos $\alpha, \beta, \gamma$, com mudança de fase $\delta$. (...) A mecânica quântica de Schrödinger, portanto, dá uma resposta definitiva à questão do efeito da colisão, mas não há questão alguma sobre qualquer descrição causal. Não se ganha nenhuma resposta à pergunta "qual é o estado depois da colisão", mas apenas para a pergunta "quão provável é um resultado específico da colisão (onde naturalmente a relação mecânico-quântica da energia deve ser satisfeita). Aqui todo o problema do determinismo vem à tona. Do ponto de vista da nossa mecânica quântica não há quantidade que em qualquer caso individual causalmente determine a consequência da colisão; mas também experimentalmente não temos até o momento razão para acreditar que existem algumas propriedades internas do átomo que condicionam um resultado definido da colisão. Devemos ter esperança de mais tarde

\footnotetext{
4 Apresentamos anteriormente uma possível forma didática de se chegar na Equação de Schrödinger propondo a enunciação do Princípio de Conservação de Energia como um problema de autovalor [7]. O leitor pode acompanhar uma discussão didática sobre o percurso original percorrido por Schrödinger para chegar na sua equação consultando [13, 14].
} 
encontrar essas propriedades (como fases ou movimentos internos) e determinar elas em casos individuais? Ou devemos acreditar que a concordância da teoria e o experimento no caso da impossibilidade de prescrever condições para uma evolução causal - é uma harmonia pré-estabelecida encontrada na não existência dessas condições? Eu pessoalmente sou inclinado a abandonar o determinismo no mundo dos átomos. Mas isso é uma questão filosófica para a qual argumentos físicos sozinhos não são decisivos [37, p. 3].

$\underline{\text { Perguntas sobre o artigo de Born de } 1926}$

(a) A visão de Born nega a visão de Schrödinger?

(b) Quais questões filosóficas são levantadas por Born?

(c) Visão semelhante já havia aparecido nos textos anteriores?

(d) Qual a realidade da função de onda na visão de Born? Qual o significado físico dela?

(e) Qual seria a alternativa à visão indeterminista que Born aponta?

Comentário: O trabalho de Born traz a natureza probabilística para o centro da descrição da mecânica quântica. Jordan já havia apresentado uma axiomatização da mecânica quântica com uma interpretação probabilística, mas Born coloca o problema de forma contundente, desafiando as bases deterministas da física. Deve-se ressaltar que, em 1927, Jordan [38] também escreve um texto, publicado na revista Nature, no qual as questões filosóficas relacionadas ao determinismo e ao realismo na mecânica quântica são discutidas.

Uma elaboração da proposta de Born daria origem ao que chamamos, hoje, de regra probabilística de Born, de acordo com a qual a $\Psi$ deve ser interpretada da seguinte forma

$$
\begin{aligned}
\int_{A}^{B} \Psi^{*} \Psi d x= & \text { probabilidade de encontrar } \\
& \text { a partícula entre } A \text { e } B
\end{aligned}
$$

Não se encontra, entretanto, tal afirmação de forma explícita no artigo de 1926. A proposta de interpretação de Born, claramente, se opõe à visão realista ondulatória de Schrödinger e a qualquer noção ondulatória materialista. A função de onda, para Born, representa uma probabilidade - não sendo claro se ela é ou não um ente real. Como ele mesmo aponta, entretanto, tal indeterminação pode estar na própria natureza, ou ainda nos falta conhecimento de fatores internos que determinam os diferentes resultados experimentais, o que seria explorado por Bohm em sua proposta de variáveis ocultas [39]. A contribuição de Born para a interpretação da mecânica teve papel crucial no desenvolvimento da Interpretação de Copenhague como fica claro em vários trechos das discussões mais filosóficas de Werner Heisenberg. Em seu livro sobre física nuclear, Born [40] discute a história da dualidade ondapartícula, passando pelas diferentes visões materialistas que defendiam tanto visões corpusculares, ondulatórias ou propriamente duais, culminando em sua visão, a qual atribui à função de onda uma nova "ontologia", não sendo pensada como uma onda usual. Uma apresentação sintética da concepção de Born sobre o problema da dualidade pode ser encontrada no seguinte trecho:
De acordo com isso, nós deveríamos conectar as equações de onda com uma imagem como essa: as ondas satisfazendo a equação não representam o movimento das partículas de matéria de forma nenhuma; elas apenas de- terminam os possíveis movimentos, ou ainda os estados, da matéria. Matéria sempre pode ser visualizada como constituindo de massas pontuais (elétrons, prótons) [41, p. 355].

\subsection{O problema da dualidade onda-partícula nos trabalhos de Niels Bohr}

Apesar de ter ficado conhecido por sua interpretação probabilística da função de onda, um dos trabalhos centrais de Max Born, enquanto professor da Universidade de Götigen, era desenvolver um programa de pesquisa sobre "A Mecânica do Átomo" [42, no qual ele e seus alunos buscavam descrever a estrutura atômica em analogia com leis da mecânica celeste, inspirados principalmente pelo modelo atômico desenvolvido anos antes pelo físico dinamarquês Niels Bohr [43. Em especial, além do seu modelo atômico, seu Princípio da Correspondência (segundo o qual as regras quânticas deveriam conduzir a resultados clássicos nos casos limites de grandes números quânticos) 44 era um conceito central nesse Programa de Pesquisa.

Primeiramente, os resultados obtidos por Heisenberg [5], mostrando que, em sistemas atômicos, posição e momento não comutavam, levaram ao desenvolvimento de uma nova mecânica - a mecânica matricial. Em especial, Born, Heisenberg e Jordan avançaram no desenvolvimento de um outro formalismo que permitia, por exemplo, elaborar o Princípio da Correspondência (desenvolvido por Niels Bohr no início da física quântica) de forma quantitativa. Esse formalismo levaria Heisenberg a desenvolver o Princípio da Incerteza em 1927 [46].

Niels Bohr [47, em diálogo com esses trabalhos, propôs em 1928 o que ficou conhecido como Princípio da Complementaridade, segundo o qual a descrição completa de fenômenos atômicos demanda o uso de descrições complementares. O Princípio da Complementaridade passou a ser uma das principais teses da Interpretação de Copenhague da Teoria. Em especial, nesse artigo, Bohr fala sobre a complementaridade entre as descrições corpusculares e ondulatórias:

No que diz respeito à luz, sua propagação no espaço e no tempo é adequadamente expressa 
pela teoria eletromagnética. Especialmente os fenômenos de interferência no vácuo e as propriedades ópticas dos meios materiais são completamente governados pelo princípio da superposição da teoria das ondas. No entanto, a conservação da energia e do momento durante a interação entre a radiação $e$ a matéria, evidenciada no efeito fotoelétrico e Compton, encontra sua expressão adequada apenas na ideia quântica de luz e proposta por Einstein [47, p. 580].

Sobre a dualidade onda-partícula, Bohr afirma

Consequentemente, os dados obtidos em diferentes condições experimentais não podem ser compreendidos dentro de um quadro único, mas devem ser considerados complementares, no sentido de que só a totalidade dos fenômenos esgota as informações possíveis sobre os objetos [48, p. 51].

Em outro texto, Bohr avança em sua noção de complementaridade:

Esse ponto é de grande importância lógica, uma vez que somente a circunstância de nos ser apresentada uma escolha entre traçar a trajetória de uma partícula ou observar os efeitos de interferência permite que escapemos da necessidade paradoxal de concluir que o comportamento de um elétron ou de um fóton deve depender da presença de uma fenda no diafragma através do qual se possa provar que ele não passa. Lidamos aqui com um típico exemplo de como os fenômenos complementares aparecem em arranjos experimentais mutuamente excludentes (cf. p. 51) e ficamos diante da impossibilidade, na análise dos efeitos quânticos, de traçar qualquer distinção clara entre um comportamento independente dos objetos atômicos e sua interação com os instrumentos de medida que servem para definir as condições em que os fenômenos ocorrem 48, p. 59].

(a) Quais os quadros são vistos como complementares nesses trechos escritos por Bohr?

(b) Qual papel o experimento ganha nessa descrição?

(c) Essa visão se opõe ao esquema de descrição da realidade da física clássica?

(d) Bohr se distancia das visões dos pesquisadores anteriores?

Comentário: Para entender a proposta do Bohr, é importante entender um pouco melhor o cenário em que o artigo de 1928 foi publicado. Até 1925, o desenvolvimento das propostas de Einstein e de Broglie, os resultados obtidos por Compton, e mesmo o átomo de Bohr, não haviam conduzido a uma ruptura clara com a física clássica. O marco da mecânica quântica é considerado por muitos o artigo de 1925 de Heisenberg, no qual ele mostra que momento e posição se comportam como matrizes (ainda que ele não tenha dito isso explicitamente). Tal artigo daria origem ao programa da mecânica matricial conduzido pelo próprio Heisenberg, Pauli, Jordan, Dirac, sob influência de Niels Bohr. A proposta inicial de Heisenberg apresentava uma quantificação do Princípio da Correspondência de Bohr, era pautado pela noção de saltos quânticos e reconhecia a descontinuidade como uma característica da escala quântica. Em 1926, por outro lado, como já discutimos, Schrödinger foi capaz de articular uma mecânica ondulatória, pautada em uma equação diferencial, que permitia uma solução contínua com uma evolução determinista (ainda que a interpretação da função de onda tenha vindo a ser probabilística). No terceiro dos quatro artigos, Schrödinger mostrou que sua mecânica ondulatória, em algum nível, era equivalente à mecânica matricial, mas a disputa pela interpretação da teoria seguia viva. Em 1927, Heisenberg escreveu seu artigo apresentando o Princípio da Incerteza, defendendo a interpretação da física quântica segundo seu programa de pesquisa 46]. Bohr, entretanto, não concordou com algumas das conclusões obtidas por Heisenberg e, após longas discussões, convenceu Heisenberg que suas conclusões demandavam o uso das descrições ondulatória e corpuscular - o que resultou em uma nota adicionada após o aceite do artigo, no período de prova ("add in proof"), no qual Heisenberg explica alguns enganos do artigo e agradece a Bohr pela discussão. O conteúdo dessa discussão teria contribuído para o esclarecimento conceitual sobre o estado da física quântica, o que seria expresso através do seu Princípio da Complementaridade, defendido no artigo de 1928 [49].

O Princípio da Complementaridade proposto por Bohr, embora muitas vezes seja identificado como apenas o Princípio da Dualidade Onda-Partícula, envolve a articulação de três princípios diferentes: a) O Princípio da Dualidade-Onda Partícula; b) O Princípio da Incerteza; e c) O Princípio da complementaridade entre coordenação espaço temporal e causalidade [50, 51]. Discutiremos, neste trabalho, apenas o Princípio da Dualidade Onda-Partícula.

Bohr percorreu um longo percurso até chegar em sua proposta da Complementaridade. Apenas a título de exemplo, inicialmente Bohr não aderiu ao uso do conceito de fóton em seu modelo atômico, referindo-se apenas à quantização de Planck [43. Ao longo dos debates que constituíram o desenvolvimento da física quântica, Bohr passou a defender que a descrição ondulatória e corpuscular são complementares e mutuamente excludentes. Isso traz uma implicação filosófica importante: a caracterização de um ente específico demanda a caracterização do aparato experimental usado para descrever 
o ente. Ou seja, conforme enuncia Pessoa Jr. [16, um experimento que permite identificar a trajetória de um elétron é um experimento de caráter corpuscular, enquanto um fenômeno que não permita identificação de trajetória, resulta no aparecimento de padrões de interferência, um fenômeno ondulatório. Assim, o objeto tem que ser descrito não apenas a partir de suas próprias características, mas em relação ao sistema experimental.

De certa forma, pode-se entender que Bohr procura a conciliação dos dois programas de pesquisa concorrentes (o de Schrödinger e o de Heisenberg) através de seu princípio de Complementaridade. Tal proposta, em certa medida, pode ser entendida como uma tentativa de encerrar o debate sobre a natureza mais profunda dos entes físicos, o que poderia ser um objeto de especulação metafísica. Ao colocar a determinação da natureza (corpuscular ou ondulatória) no experimento Bohr retoma o papel da experimentação como elemento central do desenvolvimento físico, mesmo que isso signifique, em algum nível, negar o realismo e essencialismo tradicionais da física clássica.

\subsection{O Problema da Dualidade-Onda Partícula em trabalhos mais recentes}

O Princípio da Complementaridade, conforme concebido por Bohr, coloca os fenômenos corpusculares (com trajetória bem definida) e ondulatórios (que apresentam interferência), como mutuamente excludentes. Em 1979, entretanto, Wootters e Zurek mostraram ser possível obter cenários intermediários, nos quais algum nível de reconhecimento de trajetória é possível bem como o reconhecimento de um padrão de interferência:

Uma análise detalhada da versão de Einstein do experimento de dupla fenda, na qual se tenta observar as propriedades das ondas e das partículas da luz, é realizada. A não separabilidade quântica aparece na derivação do padrão de interferência, que se mostra surpreendentemente nítido mesmo quando as trajetórias dos fótons foram determinadas com uma precisão bastante alta. Uma abordagem teórica da informação para esse problema leva a uma formulação quantitativa do princípio da complementaridade de Bohr para o caso do experimento de fenda dupla. Uma versão praticamente realizável desse experimento, à qual a análise acima se aplica, é proposta [52, p. 473].

\section{Perguntas sobre o artigo de Wooters e Zurek:}

(a) Em que medida a pesquisa se afasta da proposta de Bohr?

(b) Em que medida a pesquisa concorda com a proposta de Bohr?

(c) Que tipo de abordagem teórica os autores propõem? (d) Como essa abordagem modifica o Princípio da Complementaridade?

Comentário: Diferentemente do que propusera Bohr, o fenômeno puramente ondulatório e o fenômeno puramente corpuscular são apenas os dois casos extremos que podem ser identificados em um fenômeno quântico. É possível, como apontam Wootters and Zurek, obter situações intermediárias. Greenberger and Yasin [53] desenvolveram um experimento que corroborou essa predição. De fato, pode-se definir a grandeza distinguibilidade $D$ (capacidade de distinguir o caminho seguido por um quantom) e visibilidade do padrão de interferência $V$ (relacionado com o contraste das franjas de interferência). Cada uma dessas grandezas pode variar entre 0 e 1 . Pode-se mostrar que de uma forma geral, um experimento quântico obedece a seguinte relação [54, 55]:

$$
V^{2}+D^{2} \leq 1
$$

Ou seja, quanto maior for a visibilidade do padrão de interferência ("mais ondulatório"), menor é a distinguibilidade ("menos corpuscular") e vice-versa. Isso contraria a visão original de Bohr, que menciona apenas os casos extremos; mas mantém a possibilidade de expressar uma visão complementar entre e natureza corpuscular e ondulatória e permite que o princípio seja expresso de forma quantificada. Recentemente, apresentamos uma discussão didática sobre o problema da Dualidade Onda-Partícula (e de sua quantificação) no contexto do Interferômetro de Mach-Zehnder [56].

\subsection{Uma Síntese do Percurso Histórico Realizado}

Após discutir a visão de dualidade onda-partícula nos trabalhos dos diferentes autores, pode ser profícuo, a título de fechamento da atividade, sintetizar tudo que foi discutido. A título de exemplo, apresentamos uma Tabela 1 síntese, na qual apresentamos a identificação de cada artigo, uma síntese da visão de "dualidade onda-partícula" (indicando quando a visão não é dual de acordo com a visão apresentada nesse roteiro - reforçamos que outras definições podem levar a diferentes classificações) e o que cada artigo "nega" das visões anteriores (no sentido dado por Bachelard [7]).

\section{Considerações Finais}

Apresentamos, neste trabalho, um material didático construído a partir de trechos dos artigos originais da física quântica que apresentam a questão da dualidade onda-partícula de forma substancial. Dentro do possível, também conectamos, nos comentários, a discussão conceitual com o formalismo utilizado no artigo ou com a 
Tabela 1: Síntese das visões discutidas.

\begin{tabular}{|c|c|c|}
\hline Artigo & $\begin{array}{l}\text { Visão sobre "dualidade } \\
\text { onda-partícula" }\end{array}$ & O que "nega"? \\
\hline Einstein, 1905 & $\begin{array}{l}\text { Radiação corpuscular (tudo pode } \\
\text { ser descrito como partícula). Não é } \\
\text { uma visão dual. }\end{array}$ & $\begin{array}{l}\text { Equações de Maxwell seriam uma } \\
\text { aproximação. }\end{array}$ \\
\hline Einstein, 1909 & $\begin{array}{l}\text { Primeira visão dual (partícula com } \\
\text { um campo contínuo associado). }\end{array}$ & $\begin{array}{l}\text { "Nega" (em parte) a própria visão de } \\
1905 .\end{array}$ \\
\hline De Broglie, 1922 & $\begin{array}{l}\text { Quanta são partículas com massa } \\
\text { (visão corpuscular). Não é dual. }\end{array}$ & $\begin{array}{l}\text { "Nega" equações de Maxwell. Nega a } \\
\text { afirmação canônica do segundo } \\
\text { postulado da Teoria da Relatividade } \\
\text { Especial. }{ }^{5}\end{array}$ \\
\hline De Broglie, 1923 e De Broglie, 1924 & $\begin{array}{l}\text { Todo corpo físico possui um } \\
\text { fenômeno ondulatório associado. } \\
\text { Visão Dual }\end{array}$ & $\begin{array}{l}\text { "Nega" visão corpuscular. "Nega" } \\
\text { equações de Maxwell. }{ }^{6}\end{array}$ \\
\hline $\begin{array}{l}\text { Primeiro Artigo do Schrödinger, } \\
1926\end{array}$ & Fenômeno ondulatório puro. & "Nega" visões corpusculares. \\
\hline $\begin{array}{l}\text { Segundo Artigo do Schrödinger, } \\
1926\end{array}$ & $\begin{array}{l}\text { Fenômeno ondulatório no espaço de } \\
\text { fase. }\end{array}$ & "Nega" visões corpusculares. \\
\hline Quarto Artigo do Schrödinger, 1926 & $\begin{array}{l}\text { Função de onda está associada com } \\
\text { alguma noção de "função-peso" }\end{array}$ & "Nega" visões corpusculares. \\
\hline Max Born, 1926 & $\begin{array}{l}\text { Onda de probabilidade (Visão } \\
\text { corpuscular, mas sem possibilidade } \\
\text { de descrição determinista) }\end{array}$ & $\begin{array}{l}\text { "Nega" determinismo (um dos pilares } \\
\text { da física Clássica) }\end{array}$ \\
\hline Niels Bohr, 1928 & Princípio da Complementaridade & $\begin{array}{l}\text { "Nega" a possibilidade de um quadro } \\
\text { isolado descrever a natureza. Nega o } \\
\text { essencialismo (um dos pilares da física } \\
\text { Clássica) }\end{array}$ \\
\hline Wootters \& Zurek, 1979 & $\begin{array}{l}\text { Princípio da Complementaridade } \\
\text { quantificado }\end{array}$ & $\begin{array}{l}\text { Princípio da Complementaridade de } \\
\text { Bohr passa a ser um caso particular. }\end{array}$ \\
\hline
\end{tabular}

estrutura matemática que é vista atualmente nos livros didáticos.

Como em toda construção didática, sempre há muitos elementos que não foram incorporados. Tentamos justificar as escolhas que foram feitas para o material apresentado na seção 2, na qual apresentamos nosso quadro teórico. Entendemos, entretanto, que o presente material cumpre o papel de um material didático que contribui para discussões sobre física quântica em um nível introdutório, auxiliando os alunos a ter um primeiro contato com os trabalhos originais e, assim, fomentando uma concepção mais profunda sobre a natureza da ciência, permitindo um maior engajamento e investigação por parte dos alunos e criando uma linguagem comum entre eles e o professor, o que pode favorecer a formação da

\footnotetext{
${ }^{5}$ Conforme discutimos, ao longo do roteiro, a proposta de Louis de Broglie conduz à descrição da radiação eletromagnética com velocidade menor do que c no vácuo, sendo dependente da frequência da radiação. Como o próprio de Broglie reconhece, isso demanda uma revisão da teoria eletromagnética e da teoria da relatividade especial. Nesse sentido, negar não quer dizer invalidar a teoria, mas apenas demandar alguma ressignificação ou modificação.

${ }^{6}$ Nega no mesmo sentido explicado na nota 5.
}

zona de desenvolvimento proximal e, por consequência, o próprio processo de domínio conceitual.

\section{Material suplementar}

O seguinte material suplementar está disponível online:

Apêndice A - A relação entre energia e frequência de um quantum obtida por Einstein em 1905

Apêndice B - Equivalência entre o Princípio de Maupertuis (mecânica do ponto material) e de Fermat (Ótica) no contexto não-relativístico.

\section{Referências}

[1] F. Ostermann e M.A. Moreira, Investig. em Ensino Ciências 5, 23 (2000).

[2] A. Johansson, S. Andersson, M. Salminen-Karlsson e M. Elmgren, Cult. Stud. Sci. Educ. 13, 205 (2018).

[3] H. Kragh, Sci. Educ. 1, 349 (1992).

[4] A.F.P. Martins, Cad. Bras. Ensino Física 24, 112 (2007).

[5] W. Costa, D.E. Oliveira e J.M. Hidalgo, Alexandria 8, $151(2015)$. 
[6] D. Allchin, Sci. Educ. 13, 179 (2004).

[7] N.W. Lima, M.M. Nascimento, C. Cavalcanti e F. Ostermann, Rev. Bras. Ensino de Física 42, e20200019 (2020).

[8] B.R. Wheaton, The Tiger and the Shark: empirical roots of wave-particle dualism (Cambridge University Press, Cambridge, 1983)

[9] G.L.F. Batista, J.M.H. Drummond e D.B. Freitas, Cad. Bras. Ensino Física 32, 663 (2015).

[10] A.P.B. Silva e A. Guerra, História da Ciência e Ensino: Fontes primárias e propostas para sala de aula (Editora Livraria da Física, São Paulo, 2015).

[11] V. Briccia e A. Carvalho, Rev. electrónica enseñanza las ciencias 10, 1 (2011).

[12] O.B. Oliveira, Pro-Posições 22, 71 (2011).

[13] R. Karam, Am. J. Phys. 88, 433 (2020).

[14] R. Karam, Am. J. Phys. 88, 39 (2019).

[15] J. V Wertsch, Vygotsky and the Social Formation of Mind (Harvard University Press, Cambridge, 1985).

[16] O. Pessoa Jr., Conceitos de Física Quântica (Livraria da Física, São Paulo, 2003).

[17] R.A. Martins e P.S. Rosa, História da teoria quântica a dualidade onda-partícula, de Einstein a De Broglie (Livraria da Física, São Paulo, 2014).

[18] A. Einstein, The Collected Papers of Albert Einstein (Princeton University, Press, Princeton, 1987), v. 2.

[19] M. Planck, Rev. Bras. Ensino Física 22, 536 (2000).

[20] M. Planck, Rev. Bras. Ensino Física 22, 538 (2000).

[21] M. J. Klein, Science 157, 509 (1967).

[22] L. Broglie, J. Phys. Radium 3, 422 (1922).

[23] A. S. Goldhaber e M. M. Nieto, Rev. Mod. Phys. 82, 939 (2010).

[24] L. Broglie, Comptes Rendus 177, 507 (1923).

[25] L. Broglie, Philos. Mag. 47, 446 (1924).

[26] F. Ostermann e T. Ricci, Cad. Bras. Ensino Física 21, 83 (2004).

[27] L. Broglie, "The Wave Nature of the electron, 1929", disponível em: https://www.nobelprize.org/prizes/phys ics/1929/broglie/lecture/, acessado em 14/10/2020.

[28] N.W. Lima and R. Karam, Am. J. Phys., no prelo, 2020.

[29] L. Broglie, J. Phys. Radium 8, 225 (1927).

[30] L. Broglie, Found. Physics 1, 5 (1970).

[31] E. Schrodinger, Phys. Rev. 28, 1049 (1926).

[32] E. Schrodinger, "The Fundamental idea of Wave Mechanics - Nobel Lecture, 1933", disponível em: htt ps://www.nobelprize.org/uploads/2017/07/schrodingerlecture.pdf, acessado em 14/10/2020.

[33] E. Schrodinger, Collected Papers on Wave Mechanics (Backie \& Son Limited, London, 1928).

[34] H. Kragh, Centaurus 26, 154, (1982).

[35] L. Wessels, Stud. Hist. Philos. Sci. Part A 10, 311 (1979).

[36] C. Joas e C. Lehner, Stud. Hist. Philos. Sci. Part B Stud. Hist. Philos. Mod. Phys. 40, 338 (2009).

[37] M. Born, Zeit Phys 37, 8631926.

[38] P. Jordan, Nature 119, 566 (1927).

[39] D. Bohm, Causalidade e Acaso na Física Moderna (Contraponto, Rio de Janeiro, 2015).
[40] M. Born, Atomic Physics, (Backie \& Son Limited, London, 1969) 8th ed.

[41] M. Born, Nature 119, 354 (1927).

[42] M. Born, "The Statistical Interpretation of Quantum Mechanics - Nobel Lecture, 1954", disponível em http s://www.nobelprize.org/uploads/2018/06/born-lecture. pdf, acessado em 14/10/2020.

[43] N. Bohr, Philos. Mag. 26, 1 (1913).

[44] N. Bohr, in "The Correspondence Principle (19181923), editado por L. Rosenfeld e J.R. Nielsen, (Elsevier, London, 1976), v. 3.

[45] W. Heisenberg, Sources of Quantum Mechanics (Dover Publications, New York, 1967).

[46] W. Heisenberg, in Quantum Theory and Measurement, editado por J. A. Wheeler e W. H. Zurek, (Princeton University Press, Princeton, 1983).

[47] N. Bohr, Nature 121, 580 (1928).

[48] N. Bohr, Física atômica e conhecimento humano: ensaios 1932-1957 (Contraponto, Rio de Janeiro, 1995).

[49] B.L. van Waerden, Sources of Quantum Mechanics (Dover Publications, New York, 1968).

[50] M. Jammer, The Conceptual Development of Quantum Mechanics (McGraw-Hill Book Company, New York, 1966).

[51] W. Heisenberg, Physics and Philosophy (Penguin, London, 1958).

[52] W.K. Wootters e W.H. Zurek, Phys. Rev. D 19, 473 (1979).

[53] D.M. Greenberger e A. Yasin, Phys. Lett. A 128, 391 (1988).

[54] P. Busch e G. Jaeger, Found. Phys. 40, 1341 (2010).

[55] B.-G. Englert, Phys. Rev. Lett. 77, 2154 (1996).

[56] C.J.H. Cavalcanti, F. Ostermann, J.S. Neto e N.W. Lima, Rev. Bras. Ensino Física 42, e20190283 (2020). 